\section{THU0238 ULTRASONOGRAPHIC EVALUATION OF DISTAL PATELLAR ENTHESIS IN PATIENTS AFFECTED BY ENTHEROPATIC SPONDILOARTHRITIS}

A. Batticciotto ${ }^{1}$, G. Prato ${ }^{1}$, M. Antivalle ${ }^{1}$, M.C. Ditto ${ }^{2}$, M. Agosti $^{1}$, E. Cumbo ${ }^{1}$, R. Talotta ${ }^{1}$, F. Atzeni ${ }^{3}$, P. Sarzi-Puttini ${ }^{1} .{ }^{1}$ Rheumatology Department, ASSTFatebenefratelli-Sacco. "L. Sacco" University Hospital, Milano; ${ }^{2}$ Rheumatology Department, Città della Salute e della Scienza di Torino, Torino; ${ }^{3}$ Rheumatology Unit, Rheumatology Unit, University of Messina, Messina, Italy

Background: Enteropathic arthritis (EA) belongs to the spondyloarthritis $(\mathrm{SpA})$ spectrum of diseases and occurs in patients affected by inflammatory bowel diseases (IBD). Several works demonstrated that ultrasonography (US) is a feasible, reliable and easily accessible tool for detecting chronic and active entheseal abnormalities even in a subclinical contest in SpA patients. ${ }^{1,2}$

Objectives: To evaluate the prevalence of US entheseal involvement of the distal insertion of patellar ligament in patients affected by EA.

Methods: Twenty-two consecutive AE patients (12 with Crohn's disease and 10 with ulcerative colitis; 8 females and 14 males; mean age 44.7 years, range 18-72 years; mean $A E$ duration 10.1 years range $4-21$ years) and 18 healthy age- and gender-matched controls (8 females and 10 males; mean age 48 years, range 24-68 years) underwent an US examination (ESAOTE MyLAB 70 6-18 MHz linear array transducer) according with the validated Madrid Sonographic Enthesis Index (MASEI). Clinical and clinimetric variables were assessed in both groups according with daily clinical practice.

Results: Focusing on the $\mathbf{4} 4$ distal patellar entheses we identified a higher prevalence of all the elementary lesion analysed. In 34 entheses we identify a dishomogeneous echostructure $(77.3 \%$ vs $33.3 \% ; \mathrm{p}=0.0001)$, in 38 structural thickness (86.4\% vs $66.7 \%$; $p=0.03$ ), in 16 power Doppler positivity (36.3\% vs $16.7 \%$; $\mathrm{p}=0.04)$, in 17 presence of calcifications $(38.6 \%$ vs $16.7 \% ; \mathrm{p}=0.03)$ and in 8 entheses the presence of erosions ( $18.8 \%$ vs $0 \% ; p=0.007$ ). In the $45 \%$ of the examined patients we detected a simultaneous presence of dishomogeneous echostructure, structural thickness and power Doppler positivity suggestive for US active enthesitis at the level of the same enthesis.

Conclusions: US detectable signs of enthesopathy and enthesitis are very frequent in EA patients even when we analyse the distal enthesis of the patellar ligament alone. Further studies involving a larger number of patients are needed to confirm these preliminary data.

\section{REFERENCES:}

[1] Atzeni F, Defendenti C, Ditto MC, et al. "Rheumatic manifestations in inflammatory bowel disease". Autoimmun Rev. 2014 Jan;13(1):20-3.

[2] Wakefield RJ, Green MJ, Marzo-Ortega H, et al. Should oligoarthritis be reclassified? Ultrasound reveals a high prevalence of subclinical disease. Ann Rheum Dis 2004;63(4):382-5.

Disclosure of Interest: None declared

DOI: 10.1136/annrheumdis-2018-eular.6147

\section{THU0239 PROGRESSION OF STRUCTURAL DAMAGE ON MRI OF THE SPINE AND SACROILIAC JOINTS IN PATIENTS WITH AXIAL SPONDYLOARTHRITIS IS LIMITED: THE 5 - YEAR RESULTS IN THE DESIR COHORT}

A. Sepriano ${ }^{1}$, S. Ramiro ${ }^{1}$, R. Landewé ${ }^{2}$, M. Dougados ${ }^{3}$, D. van der Heijde ${ }^{1}$ ${ }^{1}$ Rheumatology, Leiden University Medical Centre, Leiden; ${ }^{2}$ Rheumatology, Amsterdam Rheumatology and Clinical Immunology Center (ARC), Amsterdam, Netherlands: ${ }^{3}$ Rheumatology, Hôpital Cochin, Hôpitaux de Paris, Paris, France

Background: Reliably detecting radiographic structural change in patients with axial spondyloarthritis (axSpA), especially in the sacroiliac joints (SIJ), is notoriously difficult. Magnetic resonance imaging (MRI) is an alternative for radiographs to assess structural damage. However, so far the utility of MRI in capturing change in structural damage over time has been poorly studied.

Objectives: We aimed to evaluate the change over time of structural lesions on $\mathrm{MRI}$ of the SIJ and spine in patients with axSpA.

Methods: Patients with recent onset ( $\leq 3$ years) axSpA (according to the treating rheumatologist) from the DESIR cohort were included. MRI of the SIJ (MRI-SIJ) and spine (MRI-spine) were obtained at baseline and 5 years and scored by 3 trained central readers unaware of the chronology. Structural damage in the SIJ (MRI-SIJ-STR) and in the spine (MRI-spine-STR) was defined according to 3 binary rules (A1: $\geq 5$ fatty lesions and/or erosions; $B 1: \geq 3$ erosions; and $C 1: \geq 3$ fatty lesions) and 3 continuous scores (A2: number of fatty lesions/erosions; B2: number of erosions; and C2: number of fatty lesions). For binary outcomes, structural damage was defined by the agreement of at least 2 out of 3 readers and the $\%$ of net progression by subtracting the number of patients that 'improved' from those that 'worsened' divided by the total number of patients with complete baseline and 5 year data. For continuous outcomes, the mean of the 3 readers was used and the difference between year 5 and baseline was calculated.

Results: In total, 151 and 145 patients had complete MRI-SIJ and MRI-spine data available from 3 readers, respectively. The percentages of net progression at SIJ level are summarised in the figure 1 . These were $6.6 \%, 0.7 \%$ and $7.9 \%$ for the binary outcomes A1, B1 and C1 respectively. Notably, the percentage of 'improvement' (4.6\%) was almost as high as the percentage of 'worsening' (5.3\%) for definition $\mathrm{B} 1$ ( $>3$ erosions); while no 'improvements' were seen by the 3 readers for definition $\mathrm{C} 1$ ( $\geq 3$ fatty lesions). Similar differences were seen for the mean (standard deviation) change of the 3 MRI-SIJ-STR continuous outcomes (A2: 1.02 (2.60); B2: 0.20 (1.39); and C2: 0.83 (2.20); $\mathrm{p}<0.01$ for all). MRI-spine-STR net change over time was almost absent (A1: $-0.7 \%$; B1: $0.0 \%$; $\mathrm{C} 1: 0.7 \%$ ) considering the binary outcomes, and small (though statistically significant) considering definition A2 $(0.18(0.52) ; p<0.01)$ and $\mathrm{C} 2(0.14(0.48) ; p<0.01)$ but absent for definition $B 2(0.03(0.24) ; p=0.109)$.
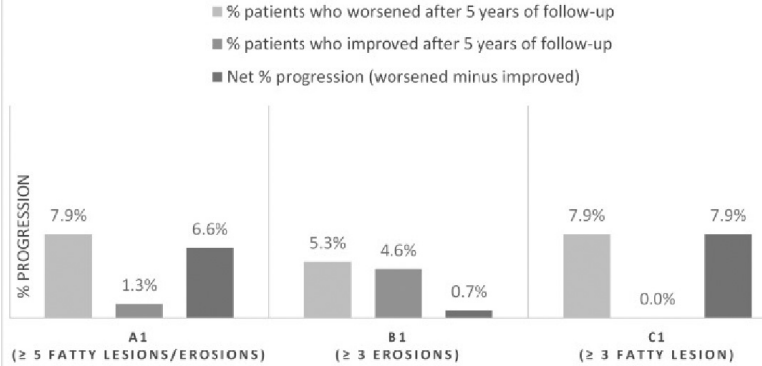

Abstract THU0239 - Figure 1. Changes in different binary MRI-SIJ-STR outcome measures. All outcomes are assessed according to the ' 2 out of 3 ' definition in the completers population ( $\mathrm{N}=151)$. MRI-SIJ-STR, structural damage on magnetic resonance imaging of the sacroiliac joints

Conclusions: These results suggest that patients with early axSpA only show modest structural progression in the MRI of the SIJ and that fatty lesions are more sensitive to change compared to erosions. In this early axSpA population, MRIdetected structural progression in the spine is very limited/absent.

Disclosure of Interest: None declared

DOI: 10.1136/annrheumdis-2018-eular.1746

\section{THU0240 THE SIZE AND FREQUENCY OF BONE MARROW OEDEMA ON SACROILIAC JOINT MRI DIFFERS IN A CLUSTER-WISE COMPARISON OF PATIENTS WITH FINDINGS SUGGESTIVE OF AXIAL SPONDYLOARTHRITIS}

A.A. Christiansen ${ }^{1}$, A.G. Loft ${ }^{2}$, K. Hørslev-Petersen ${ }^{1}$, S. Juhl-Pedersen ${ }^{3}$ U. Weber ${ }^{1}$, L.T. Hermansen ${ }^{1}$, B. Arnbak ${ }^{4}$, A. Zejden ${ }^{2}$, B. Schiøttz-Christensen ${ }^{4}$ C. Manniche ${ }^{4}$, O. Hendricks ${ }^{1} .{ }^{1}$ King Christian 10 th Hospital for Rheumatic Diseases and Hospital of Southern Jutland, Gråsten; ${ }^{2}$ Aarhus University Hospital, Aarhus; ${ }^{3}$ Rigshospitalet, Copenhagen; ${ }^{4}$ Spine Centre of Southern Denmark, Middelfart, Denmark

Background: Multiple correspondence analysis (MCA) is a statistical method that allows for the translation of data from multiple categorical variables into single coordinates per individual. When combined with cluster analysis, individuals that share phenotypic characteristics can be grouped together. The Assessment of Axial Spondyloarthritis international Society (ASAS) published classification criteria for axial spondyloarthritis (axSpA) in $2009^{1}$ that included active sacroilitis on magnet resonance imaging (MRI) of the sacroiliac joints (SIJ) defined as bone marrow oedema (BME) present in either as 2 lesions on one slice, or 1 lesion on 2 consecutive slices. ${ }^{2}$ It has been shown that extent of BME is associated with risk of radiographic progression. ${ }^{3}$

Objectives: To identify phenotypes in low back pain (LBP) patients recruited from primary care with findings suggestive of early axSpA and to assess differences in size and frequency of BME lesions on SIJ MRI.

Methods: Age, gender and the ASAS SpA features (SIJ BME on MRI, HLA-B27, inflammatory back pain, arthritis, heel enthesitis, uveitis, psoriasis, inflammatory bowel disease, good response to NSAIDs, family history of SpA, but not dactylitis (not observed) or radiographic sacroilitis) of 134 LBP patients who either met of were one feature short of meeting the ASAS classification criteria for axSpA were analysed by MCA and subsequent k-means cluster analysis in order to identify various clinical phenotypes. The above listed SpA features, and if present, the 